\title{
Jenofonte y su ideal de belleza femenina
}

Xenophon and his Ideal of Female Beauty

\author{
Carolina Olivares ChÁvez \\ Centro de Estudios Clásicos, IIFL, Universidad Nacional Autónoma de México \\ caro.hiparquia@gmail.com
}

\begin{abstract}
RESUMEN: En este artículo se analizan dos pasajes donde Jenofonte describe dos clases de mujeres, el primer texto se localiza en Económico, X, 1-13, y el segundo pertenece a Memorables, II, 22-23, aquí se relata el mito de Heracles en la encrucijada. Ambos pasajes se complementan y permiten inferir cuál era el ideal de belleza femenina para este socrático.
\end{abstract}

ABSTRACT: This article discusses two passages where Xenophon describes two kinds of women; the first text is located in Oeconomicus, X, 1-13, and the second belongs to Memorabilia, II, 22-23, here tells the myth of Heracles at the crossroads. Both passages are complementary and allow us to infer what was the ideal of feminine beauty to this Socratic.

PAlABRAS ClAVE: belleza, Económico, Jenofonte, Memorables, mujer, educación.

KeY WORds: Beauty, Oeconomicus, Xenophon, Memorabilia, Woman, Paideia.

RECIBIDO: 5 de abril de 2015 - ACEPTADO: 30 de junio de 2015.

Durante el siglo IV a. C. se produjo en Atenas el auge del arte y literatura con temática erótica; la filosofía no se quedó atrás, sino que también se interesó por tratar las adecuadas relaciones entre hombres y mujeres. ${ }^{1}$ Hay autores como Colombani quienes consideran que las dos fuentes principales para construir el modelo de lo femenino en Occidente son: a) el discurso mítico griego, de raíz hesiódica, donde la mujer nace como un castigo a partir de la transgresión de Prometeo, y b) la mujer en el relato clásico, cuya figura paradigmática es la esposa de Iscómaco. ${ }^{2}$

A todas luces la paideia es un tema central en las obras de Jenofonte, porque para él educación es la base del oikos y de la pólis. Por eso me propongo demostrar que el historiador aprovecha un asunto en apariencia superficial para en realidad ocuparse de la educación femenina: con el pretexto de los cosméticos y de las artimañas de las mujeres, Jenofonte plantea el dilema entre la belleza física y la verdadera belleza del alma femenina.

\footnotetext{
${ }^{1}$ Cf. Mirón Pérez 2012, p. 169.

${ }^{2}$ Cf. Colombani 2010, p. 2.
} 


\section{La bella apariencia femenina}

En el Económico, una joven recién casada, menor de quince años, deseosa de agradarle a su marido, adopta lo que podría considerarse una actitud habitual de las mujeres con buena posición económica: con la finalidad de verse más hermosa, en una ocasión, la chiquilla recurrió a los artilugios de los cosméticos. Esa vez la muchacha usó demasiado maquillaje para aparentar ser más blanca, utilizó mucho rubor para simular una tez más sonrosada y se puso unos zapatos de tacón para verse más alta. ${ }^{3}$

Tan pronto como Iscómaco la observa arreglada de tal manera, le hace una serie de preguntas y manifiesta con claridad que él prefiere la belleza natural, ya que la pareja se une para disfrutar de sus cuerpos. El hacendado comenta que es mucho mejor tener un cuerpo fuerte y sano, con buen color, por eso él mismo procura cuidar su aspecto físico en lu-

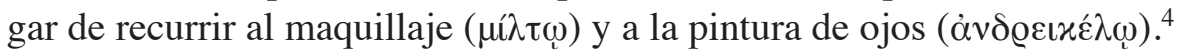
El marido le dice con franqueza a la joven que no le agrada que se pinte, porque lo que causa más placer es el cuerpo puro del ser humano. ${ }^{5}$

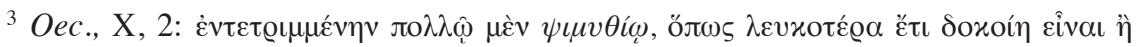

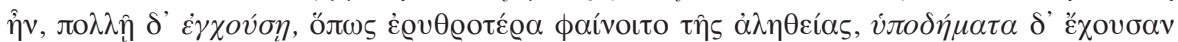

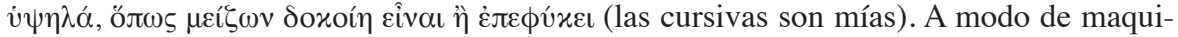
llaje, las mujeres de esa época usaban psimythion, una sustancia de carbonato de plomo que les daba un color blanco en el rostro.

La ancusa posee raíces tintóreas de color rojo de la especie Alcanna tinctoria L., planta muy común en la cuenca mediterránea. Se trata de un alcaloide conocido como alcannina. En la antigüedad las griegas emplearon este pigmento como rubor para las mejillas (cf. Pomeroy 1994, p. 306, y Farmacia Museo Aramburu, s. v. ancusa).

Los coturnos eran el calzado femenino de calle y el de Dioniso. Estos zapatos de madera tenían suela muy gruesa que aumentaba algunos centímetros la altura de los actores. Según algunas fuentes, el calzado con la suela de veinte centímetros de grosor y pintada de colores apareció en la época helenística (cf. Kriúkova 2008, p. 34).

${ }^{4}$ Oec., X, 5. Los varones también solían pintarse, el milto era un maquillaje que les daba a los hombres una tez bronceada, propia de quien trabaja fuera del oikos y se expone al sol: "una cara morena representaba fuerza y salud" (Kriúkova 2008, p. 28.

El andreikelon era un polvo para los ojos (cf. Pomeroy 1994, p. 306). Jenofonte dice que Astiages, abuelo de Ciro, usaba cosméticos: se pintaba los ojos, usaba rubor y peluca, estos adornos eran una tradición entre los medos. Gracias al maquillaje el pequeño

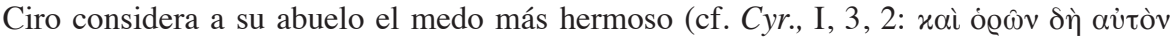

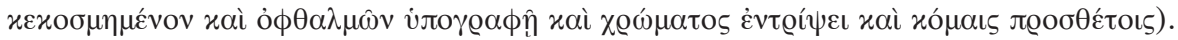

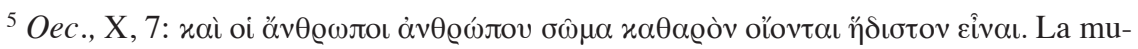
jer casada no utiliza cosméticos ni adornos, pues esto va en contra de la naturaleza (cf. 
Iscómaco señala que los cosméticos permiten brindar una falsa apariencia a los extraños, pero entre seres que conviven diario no sirven. Le hace comprender a la joven que es mejor presentarse ante la pareja tal cual uno es, para no engañarla al ofrecerle una bella apariencia; es preferible disfrutar las cualidades que en verdad tiene el otro, en lugar de quedarse con la mera ficción, este comportamiento provoca que él no confíe en su mujer. ${ }^{6}$

El terrateniente rechaza el uso del maquillaje y de las trampas femeninas, porque al convivir cotidianamente es fácil descubrir los trucos, al contemplar el verdadero rostro de alguien antes de pararse de la cama, antes de arreglarse, al sudar, al llorar o cuando se baña. ${ }^{7}$ De ahí en adelante su esposa renuncia a los cosméticos y deja de aparentar lo que no es. ${ }^{8}$ Iscómaco agrega que las mujeres sentadas de manera ostentosa están entre las catalogadas como muy arregladas y engañosas. ${ }^{9}$

Castellanos Moreno 2006, p. 23). El arreglo corporal se torna peligroso porque refleja la inmoralidad. Los artificios de la vestimenta y del maquillaje pueden engañar a un hombre “desprevenido y ocultar el 'verdadero' aspecto de las mujeres - esto es, disimular la vejez, los malos olores y otros defectos físicos - con el objetivo de confundir la percepción que el amante o el marido tienen de ellas" (Palacios 2014, p. 99).

Los antiguos griegos y romanos se pronuncian en contra de ciertos atuendos, maquillajes y adornos, debido a que disimulan el verdadero estado físico de una mujer y ayudan a ocultar su verdadera condición moral. Por lo tanto, la alteración del propio cuerpo por medios artificiales redunda en la manipulación y el control del cuerpo y de la voluntad masculina (cf. ibid., p. 100).

${ }^{6}$ Cf. Oec., X, 3-7. El comediógrafo Alexis enumera varios trucos empleados por las heteras: las de estatura baja le cosen un corcho a sus zapatos; las altas usan zapatos bajos y encogen la cabeza sobre su hombro, para simular ser más bajas; se pintan las cejas con hollín; las morenas se untan psimythion o albayalde; las que son pálidas se ponen rubor; si tienen una parte de su cuerpo muy bella procuran mostrarla desnuda, etc. Así ocultan sus defectos y resaltan sus encantos. Cf. Alexis, 103 K.-A., apud Ath., XIII, 568a-d (13.23.1-31). Cf. en especial Sanchis Llopis 2014, p. 52.

En otra parte, Alexis alude al psimythion, comenta que las heteras se aplican un rubor de moras en las mejillas, se mofa porque con el calor del verano se les escurre la tinta negra de los ojos, y el rubor de sus mejillas deja surcos en su cuello, agrega que al humedecerse su cabello con el sudor y tocar el albayalde de su cara parece que su pelo se vuelve canoso (cf. Ath., XIII, 557f-558a (13.6.3-10), y Sanchis Llopis, 2014, p. 53).

${ }^{7} \mathrm{Cf}$. Oec., X, 8.

${ }^{8}$ Cf. ibid., X, 9. Según esto hay dos tipos de mujeres: la buena cuida el oikos, la mala resulta peligrosa por su atractivo (cf. Dowden 1995, p. 52).

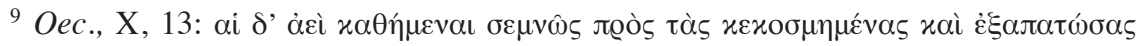

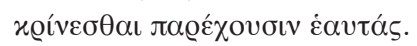


Al analizar los estereotipos femeninos, Picazo Gurina señala lo siguiente:

En la cultura griega, la ropa no hacía necesariamente al hombre, pero sí a la mujer [...], la ropa y los ornamentos complementarios servían para identificar la condición femenina en la literatura y el mito griegos, fluctuando de la asociación negativa entre mujeres, ornamento y vanidad a la conexión entre modestia y vestidos. ${ }^{10}$

Por lo que atañe al maquillaje, en ese tiempo tanto las casadas como las heteras lo usaban mucho, sólo en caso de luto se consideraba de mal gusto utilizarlo. Las asistentes a los misterios tampoco empleaban afeites. ${ }^{11}$ Se creía que una piel blanca era más atractiva, ya que indicaba que la mujer gozaba de buena posición económica, porque permanecía bajo techo y no tenía la necesidad de salir a la intemperie. Para lograr este efecto, ellas recurrían a polvos blancos y se protegían del sol con una sombrilla. ${ }^{12}$ Cabe recordar que Homero describe a Hera como la diosa "de blancos brazos" ( $\Lambda \varepsilon v x \omega ́ \lambda \varepsilon \varepsilon v o \varsigma)$, la princesa Nausícaa también recibe este epíteto. ${ }^{13}$

Por su parte, López Melero asevera que, entre más blanca era la mujer, se pensaba que era más femenina y más fértil, esto atraía al varón. Debido a este canon de belleza, las mujeres se esforzaban por conseguir a toda costa una piel blanca:

testimonios literarios y arqueológicos [...] indican que la utilización del carbonato de plomo era muy común. Pero su uso prolongado era nocivo, ya que destruía la epidermis e incluso provocaba la muerte si se tragaban algunas partículas debido a la reacción de los ácidos gástricos. Pero su gran capacidad de cubrir - incluso los efectos perniciosos de su aplicación-y su

${ }^{10}$ Picazo Gurina 2008, p. 89.

${ }^{11}$ Cf. Zaragoza, en Jenofonte 1993, p. 254, n. 32, y Pomeroy 1999³, p. 102.

${ }^{12}$ Cf. Pomeroy $1999^{3}$, p. 102. Desde la antigüedad el ideal de belleza femenina se caracterizaba por la piel blanca, mejillas sonrosadas y cabello rubio (cf. Omatos 1992, p. 171).

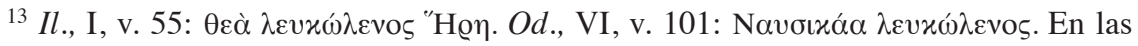
pinturas cretenses se usa el blanco para la piel femenina y un tono marrón para los varones, en esto los artistas adoptaron la convención egipcia (cf. Pomeroy 1994, p. 305, y Masvidal y Picazo 2005, pp. 127 y 136). 
resistencia frente al agua, convirtieron al "blanco de plomo" en el maquillaje más común. ${ }^{14}$

Entre los antiguos griegos, la estatura era otro parámetro de belleza, sobre todo si se trataba de heteras, por eso algunas mujeres usaban calzado con tacón; desde aquella época había una gran variedad de sandalias y zapatillas. ${ }^{15} \mathrm{Al}$ principio sólo los actores de teatro usaban el coturno para verse más altos e impresionar a los espectadores; cuando las mujeres, principalmente heteras, se percataron de que la estatura resultaba un arma de seducción, también recurrieron a esta clase de zapato, "punto de partida de las innumerables variantes de calzado femenino que, a través de la historia, ha tenido varias suelas o altos tacones". ${ }^{16}$ La altura, además de ser indicador de belleza femenina, mostraba el alto estatus social de la mujer. ${ }^{17}$

La postura de Jenofonte con respecto al maquillaje ha llamado la atención de varios estudiosos, quienes lo consideran como el primer autor antiguo que censura el uso de los cosméticos, entre ellos está Omatos, quien informa que los escritores antiguos rechazaban el exagerado esmero con que las mujeres se arreglaban, pues invertían mucho tiempo en eso y abusaban del maquillaje con tal de lucir hermosas. En el Económico Jenofonte está en contra de la bella apariencia lograda con artificios. ${ }^{18}$ Omatos asevera que un reproche constante hacia las mujeres

${ }^{14}$ López Melero 2010, p. 24. El carbonato de plomo proporcionaba una palidez vistosa, pero envenenaba: el plomo absorbido por la piel ocasionaba trastornos digestivos, mareos, disnea, parálisis de las extremidades, dolores de cabeza y en ocasiones ceguera y muerte.

${ }^{15}$ Cf. Zaragoza, en Jenofonte 1993, p. 254, n. 32; Pomeroy $1999^{3}$, p. 101, y González Almenara 2003, p. 375.

${ }^{16}$ Fernández 2012.

${ }^{17}$ Cf. Pomeroy 1994, p. 306.

${ }^{18}$ Cf. Omatos 1992, pp. 171-172. Cf. ibid., pp. 163-164, 167. Zaragoza sugiere que el historiador ateniense es el primero que se declara a favor de la belleza natural de la mujer (cf. Jenofonte 1993, p. 254, n. 32). Salvo Ovidio, los escritores griegos y latinos censuraron que las mujeres decentes recurrieran a los cosméticos (cf. Pomeroy 1994, pp. 304-305).

En el s. IV d. C., Gregorio Nacianceno compuso un poema contra las mujeres que se maquillan y se arreglan en exceso, allí estableció la antítesis entre la virtuosa mujer casada y la malvada prostituta. Dicho autor cristiano se pronuncia a favor de la austeridad de la esposa y censura el lujo y derroche de las cortesanas (cf. Camps-Gaset 2014, pp. 381-390, y Difabio 2006, p. 74, n. 5). 
son "las artes a las que aquellas recurren en su afán por cazar a los hombres, recurriendo a tintes, afeites, perfumes, postizos, etc., con los cuales esconden sus defectos y aparentan ser más bellas". ${ }^{19}$ Según esto, no era correcto que gracias a las pinturas las mujeres respetables disimularan sus imperfecciones y signos de la edad. ${ }^{20}$

De acuerdo con López Melero, en el Económico, Jenofonte plantea un problema entre la estética y la ética en relación con el erotismo, pues "la coquetería quedaba, así, disociada de la sophrosune". ${ }^{21}$

A mi juicio, la aversión que el historiador siente hacia los cosméticos y la falsa apariencia femenina es resultado de la educación que recibió, donde la mitología desempeñó un papel muy importante. La seducción y el engaño aparecen en la Ilíada, además de la guerra desatada por la bella Helena, Homero describe con lujo de detalles el modo en que Hera se esmera en su arreglo personal, con miras a seducir a Zeus y distraerlo del combate. ${ }^{22}$ En la Odisea también hay varias mujeres seductoras y perversas, vinculadas al mundo de los muertos: Circe, Calipso o las Sirenas; son personajes femeninos que atraen con su bella voz y con su cuerpo, y que causan infortunios a los hombres. ${ }^{23}$

${ }^{19}$ Omatos 1992, p. 170. Las griegas teñían su cabello con colores ébano, miel, rubio dorado, rojo o castaño rojizo. Durante las representaciones teatrales, quienes interpretaban a Electra, Ifigenia, Helena, Antígona y Fedra usaban pelucas de tono rubio dorado o rubio cobrizo, un color raro entre los helenos "y símbolo implícito de la belleza, la juventud y la fuerza, o del carácter divino” (Kriúkova 2008, pp. 16-17).

${ }^{20}$ Cf. Pomeroy 1994, p. 304. Las mujeres decentes evitaban maquillarse en exceso, ya que los cosméticos eran los artificios habituales de las cortesanas y de las mujeres viejas (cf. Salmon 1977, p. 1263).

${ }^{21}$ López Melero 2010, p. 25. Es importante añadir que "la cosmética y la culinaria se refieren a la adulación del cuerpo y serían actividades ligadas a las mujeres. La primera sustituye a la verdadera corrección de las imperfecciones corporales que corre a cargo de la gimnasia, actividad vedada a las mujeres de la Atenas clásica. La cosmética era más utilizada por las cortesanas" (González Suárez 1994, p. 53).

${ }^{22}$ Cf. Il., XIV, vv. 170-223.

${ }^{23}$ Cf. Zaragoza Gras 2006, p. 21. Dicha autora aclara que este tipo de mujeres simboliza "la feminidad maligna, depravada y peligrosa, y las vidas de todas ellas ofrecen un modelo negativo, dado que cuestionan la validez de la sumisión y de la devoción familiar. Son mujeres con una elevada autoestima y conscientes de su valía, cualidades que chocan frontalmente con la idea de feminidad virtuosa inventada por los hombres" (ibid., p. 29). Pandora, Helena, Circe, las Harpías o las Sirenas, sirvieron para construir la imagen de la astucia femenina capaz de arruinar al hombre gracias a su atractivo erótico. Junto a dichos personajes, en los mitos griegos también hay demonios femeni- 
La desconfianza que inspira una mujer que realza su belleza mediante recursos artificiales remite a la tipología de Semónides de Amorgos, para quien esta clase de seres evoca a la mujer-yegua, pues es hermosa, pero evita el trabajo y las penalidades, es inútil para los quehaceres domésticos, enamora al varón con sus artimañas y sólo sabe acicalarse; si bien para los demás hombres resulta un espectáculo digno de verse, se convierte en una calamidad para su esposo. ${ }^{24}$ Es preciso agregar que, al usar perfumes y cosméticos caros, la mujer-yegua representa un peligro para la economía del marido, porque invertir en pinturas, vestidos costosos y adornos representa un gasto superfluo. ${ }^{25}$

Otra influencia relevante en la mentalidad de Jenofonte es la ejercida por Hesíodo a través del mito de Pandora. En sus obras, el poeta de Ascra la califica como un "bello mal" y como una "gran desgracia"

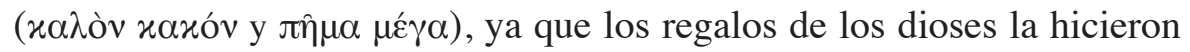
irresistible para los mortales debido a su hermosa apariencia. ${ }^{26}$ Además del bello cuerpo que le dio Hefesto a Pandora, Atenea la adornó y ciñó, la Persuasión y las Gracias le pusieron áureos collares, y las Horas le

nos y monstruos como Medusa, "seres intermedios entre la divinidad y el hombre (las llamadas Empusas o Lamias), cuyas fuerzas sobrenaturales originaron leyendas sobre la capacidad destructiva, hipnótica y vampiresca de la mujer” (Escartín Gual 2007-2008, p. 58).

${ }^{24}$ Semon. 8 [7 D.], vv. 57-70. En cuanto al nombre correcto de este poeta yámbico, remito a Brasete, quien informa que "Algumas dificuldades suscitou ainda a grafia do nome ‘Semónides', que, na Antiguidade, oscilou entre uma forma com lıl $\Sigma \mu \omega v i ́ \delta \eta \varsigma$ e outra com $|\varepsilon| \sum \varepsilon \mu \omega v i ́ \delta \eta \varsigma$. Um gramático antigo do século vi a. C. atesta, no entanto, que o nome deste poeta se escrevia com $|\varepsilon|$, diferenciando-se assim do homónimo poeta de Ceos do século v a. C.” (2003, p. 39, n. 1).

${ }^{25}$ Cf. Too 2001, p. 68, con respecto a Semon., 7, vv. 68-70.

${ }^{26}$ Cf. Th., vv. 585-593, y Op., vv. 81-82, 89. Los mitos ayudaban a fomentarles tanto a los hombres como a las mujeres el decoro y la moderación (sophrôsyne), que los hacía evitar los excesos, para que pudieran cumplir con su papel en la sociedad (cf. Pérez Miranda 2009, p. 244). Es así como en el imaginario griego la mujer malvada "tendrá un cuerpo tentador y su belleza, unida a la disposición al engaño que le es propia, la llevará a ser considerada una adversaria por los hombres [...] Pero la belleza de la perversa no es fuente de placer sino de destrucción. La perversidad de las mujeres que además son bellas no radica en lo que hacen sino en cómo son. Así, Helena o Circe son provocadoras; son conscientes del poder que poseen y lo utilizan en beneficio propio. Es decir, en la práctica activa de la seducción se utiliza la belleza como ventaja, pero procurando no levantar sospechas. He aquí otra de las características vetadas a la mujer, la voluntad astuta" (Zaragoza Gras 2006, p. 30). 
colocaron una guirnalda de flores. ${ }^{27} \mathrm{El}$ poeta le aconseja a su hermano Perses que no se deje engañar por una mujer de amplias caderas y palabras seductoras. ${ }^{28}$

Cuando Zeus ordenó la creación de Pandora, concibió a la mujer como un mal para los varones. Al ataviarla con muchos adornos, los dioses le concedieron los rasgos femeninos por excelencia: la hermosa, graciosa y púdica apariencia junto con el arte de tejer; pero también le dieron mente de perra, mentiras, palabras seductoras y conducta engañosa. ${ }^{29}$ A partir de tal relato la belleza y los adornos femeninos se convierten en una poderosa arma de seducción que atrae a los hombres:

El cuerpo de Pandora procede de la arcilla lo mismo que un objeto de cerámica, hermoso pero vacío, y los dones divinos se dirigen a convertir ese atractivo maniquí en portador de todos los simulacros que provocarán los males que afligirán a la condición humana. [...] Pandora tiene un hermoso exterior pero un interior dañino. ${ }^{30}$

Desde mi punto de vista, la postura que muestra el historiador hacia los artificios para aparentar un hermoso físico se derivan también de su contacto con su maestro Sócrates, quien recomendaba enfáticamente abstenerse de los seres bellos, porque no es sencillo disfrutarlos sin perder la cordura. ${ }^{31}$ Según el sabio, un solo beso de una persona guapa y atractiva es capaz de transtornar a un hombre sensato y prudente, de

${ }^{27}$ Cf. Hes., Op., vv. 60-76. Al ser "fabricada por los dioses", Pandora pertenece al ámbito de la "técnica", de lo "artificial", se encuentra "en lo más bajo del orden ontológico - en la línea del no-ser-, considerada un simulacro, un seductor engaño o señuelo que los dioses tenderán al hombre" (Escartín Gual 2007-2008, p. 57).

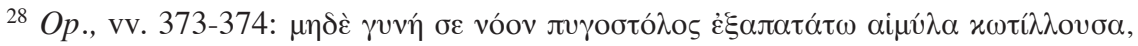

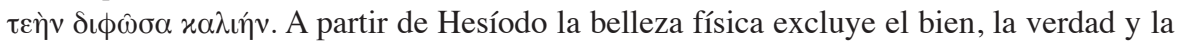
justicia. Los autores posteriores entenderán la figura del hombre de bien como básicamente masculina (cf. Beltrán Almería 2006, p. 7).

${ }^{29} \mathrm{Cf}$. Hes., Op., vv. 60-82. El poeta afirma que Zeus creó a las mujeres como un mal

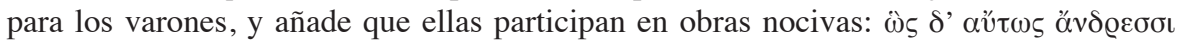

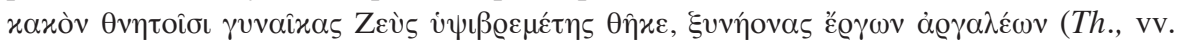
600-602). La misma idea se encuentra en $O p$., vv. 57-58.

${ }^{30}$ Picazo Gurina 2008, pp. 34-35. Electra llama malvada a una mujer que se embe-

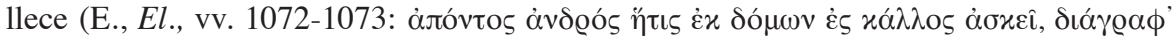

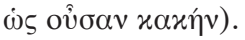

${ }^{31}$ Cf. Mem., I, 3, 8. A partir de esta observación, Sócrates y Jenofonte dialogan sobre los inconvenientes de dejarse seducir por la belleza (cf. ibid., I, 3, 8-13). 
manera que dé volteretas sobre cuchillos y brinque en el fuego. ${ }^{32} \mathrm{El}$ beso de una beldad convierte de inmediato en esclavo a un hombre libre, lo hace derrochar su fortuna en placeres nefastos, le quita tiempo para pensar en lo "bello y bueno", mientras lo obliga a preocuparse por cosas que ni un loco tomaría en cuenta. ${ }^{33}$ Sócrates establece un símil entre las personas bellas y las tarántulas, porque estos pequeños animales sólo con tocar con su boca a un ser humano le ocasionan mucho dolor e incluso lo dejan sin sentido. ${ }^{34}$ Por su parte, las personas bellas son más peligrosas que dichos arácnidos, puesto que no hace falta que toquen a los demás para inocular algo que los enloquece, basta con que alguien los mire a la distancia. Y ya que los seres hermosos hieren de lejos, el maestro de Jenofonte recomienda huir a toda prisa siempre que aparezca alguien bello. ${ }^{35}$

En torno al peligro que representa un individuo bien parecido, Sócrates advertía que el hombre que se casa con una mujer hermosa con la idea de disfrutar de ella ignora en realidad si, a causa de su misma belleza, será desdichado. ${ }^{36} \mathrm{Al}$ referirse a Alcibíades, el filósofo afirma que, por su singular belleza, una multitud de mujeres distinguidas lo acosaron, y fue corrompido por muchos hombres poderosos debido a su influencia en la polis y entre los aliados; y, dado que el demos lo honraba sin que él se esforzara en nada, Alcibíades se confió y se descuidó a sí mismo. ${ }^{37}$

Por lo que concierne a su postura personal, el filósofo rechazaba con mayor facilidad a los jóvenes bellos y atractivos, que a los individuos más feos y menos agraciados. ${ }^{38}$

${ }^{32}$ Cf. Mem., I, 3, 10 .

${ }^{33}$ Cf. ibid., I, 3, 11.

${ }^{34} \mathrm{Cf}$. ibid., I, 3, 12.

${ }^{35}$ Cf. ibid., I, 3, 13. En otro pasaje Sócrates dice que, al observar a alguien bello, de inmediato surge el deseo de tocarlo, y al marcharse se siente añoranza (cf. ibid., III, 11, 3). Ciro el Viejo también evita mirar a los seres bellos, para no sucumbir ante Eros (cf. Cyr., V, 1, 16).

${ }^{36}$ Cf. Mem., I, 1,8 .

${ }^{37}$ Cf. ibid., I, 2, 24. En IV, 2, 35, el sabio afirma que, debido a su belleza, muchas personas son corrompidas por quienes se enloquecen ante los encantos juveniles. Sostenía que el hecho de que alguien venda su belleza a cambio de dinero se denomina prostitución (cf. ibid., I, 6, 13).

${ }^{38}$ Sócrates estaba consciente de que es muy difícil encontrar a un ser humano que tenga todos sus miembros irreprochables, es decir, perfectamente bellos (cf. ibid., I, $3,14)$. 
En Memorables, III, 11, 1-18, el historiador describe una escena donde dialogan la hetera Teodota y Sócrates. La apariencia y el comportamiento de esta mujer coinciden con lo que Iscómaco no quiere para su esposa.

Desde que inicia la conversación se especifica que Teodota era una mujer cuya belleza subyugaba la razón, ella convivía con los varones que lograban "persuadirla". ${ }^{39} \mathrm{Su}$ hermosura era tanta que los pintores acudían a su casa para tomarla como modelo, dependiendo de aquello que el artista quisiera pintar, ella mostraba la parte de su cuerpo que más le conviniera. ${ }^{40} \mathrm{Al}$ escuchar esto, Sócrates se anima a visitarla, para comprobar hasta que grado los rumores eran ciertos.

Cuando el filósofo y sus amigos llegan a la casa de Teodota, ella está posando para un pintor y se quedan a contemplarla. En esta parte del relato, Jenofonte sugiere que, en lugar de actuar con recato, ella disfruta ser vista por los varones, a propósito exhibe sus encantos. Sócrates reconoce que la hetera es la más beneficiada con ese encuentro, pues sabe que sus admiradores incrementarán su fama al propagar lo bella que es. Esto era inapropiado para una ciudadana ateniense, quien vivía encerrada en su casa, debía rehuir el contacto masculino, tenía que ocultar su cuerpo y debía evitar que se hablara de ella. ${ }^{41}$

En cuanto a su apariencia, Teodota y su madre llevaban ricos vestidos y accesorios, incluso sus sirvientas tenían buen aspecto y se encontraban muy arregladas. ${ }^{42}$ No resulta extraño que la hermosa mujer ponga mucha

39 Teodota fue amante de Alcibíades, lo acompañó en sus campañas y cuando lo asesinaron en Frigia ella lo hizo incinerar (cf. Zaragoza, en Jenofonte 1993, p. 140, n. 133). En la Ilíada, Hera y Afrodita reconocen que el amor y el deseo son tan poderosos que logran someter a los dioses y a los mortales, incluso al hombre más juicioso (cf. Il., XIV, vv. 198-199 y 216).

${ }^{40}$ Las fuentes antiguas mencionan a dos mujeres de extraordinaria belleza que fueron modelos de artistas y estuvieron vinculadas con filósofos, por eso han trascendido como paradigma de hetera: Friné y Teodota (cf. Aparicio Villalonga 2007-2008, pp. 9-10, y Galí 2005, p. 3).

${ }^{41}$ En el Áyax de Sófocles se dice que, entre las mujeres, el silencio es adorno (v.

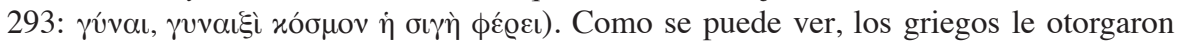
un valor positivo al silencio femenino, esto implicaba que las mujeres no hablaran en público y que se hablara muy poco de ellas (cf. Picazo Gurina 2008, p. 11).

${ }^{42}$ Cf. Mem., III, 11, 4. Los peinados, la indumentaria y los accesorios servían para atraer la atención (cf. Picazo Gurina 2008, p. 150). Había quienes pensaban que la belleza más grande escondía un alma miserable (cf. Beltrán Almería 2006, p. 1). Por 
atención en enfatizar sus atributos, porque las heteras estaban obligadas a "resaltar su feminidad a través del aspecto físico y sus encantos. Acompañando su exotismo, es proverbial la belleza y el encanto de estas mujeres. [...] Su apariencia es uno de sus principales atributos". ${ }^{43}$

Aunque la hetera finge ingenuidad, Sócrates le dice que entre las artimañas que ella usa para atrapar amantes está su cuerpo (que funciona como red) y un espíritu que entre otras cosas le ha enseñado a mirar para agradar, a hablar para seducir. ${ }^{44}$

\section{La verdadera belleza femenina}

Luego de escuchar los argumentos de su esposo, la muchacha obedece y deja de pintarse. De ahí en adelante siempre se mostró limpia ( $\varkappa \alpha \theta \alpha \varrho \alpha ́ v)^{45}$ y discreta, y le preguntó a Iscómaco qué podría hacer para en realidad ser bella y no sólo aparentarlo. ${ }^{46} \mathrm{El}$ marido le aconsejó lo siguiente:

otro lado, Teodota sigue un comportamiento semejante al de Neera, otra famosa hetera: "gastar dinero en afeites, joyas y vestidos; beber en el sympósion junto a sus amantes; ser activa sexualmente; mostrarse en público y tener movilidad espacial transforman a Neera en una mujer derrochadora, borracha, lujuriosa y libertina, que cede y es activa ante el placer y que, por el hecho de ser conocida, es considerada una mujer 'pública', la antítesis de la mujer pudorosa [...]. Son éstos atributos propios del género masculino que, al darse en el género 'equivocado', se conceptualizan como negativos" (Molas Font 2006, pp. 121-122).

${ }^{43}$ Castellanos Moreno 2006, p. 37. Cf. también Sanchis Llopis 2014, p. 59. Este investigador asevera que la codicia es otro vicio característico de las heteras devoradoras de hombres, por eso Anaxilao las compara con los animales mitológicos más nocivos: Escila, Caribdis, Esfinge, etc. (cf. ibid., p. 53).

${ }^{44}$ Cf. Mem., III, 11, 10. Gorgias, en el Encomio de Helena, se da cuenta de que existe un paralelismo "entre la potencia seductora de la palabra a través del oído y la potencia seductora de la imagen a través de la vista" (Galí 2005, p. 7). Por otra parte,

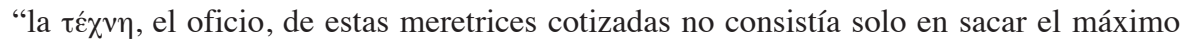
provecho de sus encantos físicos [...], sino que incluía también la seducción a través de la zalamería y la pretensión de ofrecer al cliente la mejor de las compañías" (Sanchis Llopis 2014, p. 59). Las heteras como la bella Teodota se visten para cautivar a los hombres, al igual que la araña, se visten para matar (cf. Goldhill 2010, p. 179).

${ }^{4}$ Oec., X, 9. La limpieza, entendida también como pureza, es una característica

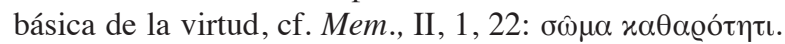

${ }^{46}$ Cf. Oec., X, 9. Kó $\lambda \lambda$ os designa a la belleza física, aquella que inspira pasión o amor. Dicha cualidad resulta positiva, siempre y cuando la acompañe la virtud (cf. Konstan 2012, p. 142). 
- La mujer en verdad bella se ejercita y cuida su cuerpo. Conviene recordar que Licurgo se opuso a que las espartanas llevaran una vida inactiva y dedicadas al trabajo de la lana (para eso bastaban las esclavas), como su principal deber cívico era procrear ciudadanos, el legislador dispuso que ellas también hicieran ejercicio físico, incluso organizó carreras y pruebas de fuerza para ellas, convencido de que una mujer y un hombre vigorosos concebirían hijos robustos. ${ }^{47}$

Gracias a su contacto directo con Esparta, Jenofonte se muestra a favor de que también la ciudadana ateniense se ejercite para estar en perfectas condiciones. ${ }^{48}$ En esta obra el autor ve a las tareas domésticas como actividad física que redunda en la salud y el bello aspecto de la esposa.

En vez de recurrir a los cosméticos para conseguir una buena apariencia, es necesario que la mujer logre la verdadera belleza física al no permanecer siempre en el oikos sentada cual una esclava, al dedicarse al telar como una señora, al enseñarle a otros lo que ella domina y al esforzarse por aprender lo que ignora. Debe supervisar a los demás y recorrer la casa para comprobar que todo esté en orden; así, al mismo tiempo que cumple con sus responsabilidades, pasea. Iscómaco le aclara a la muchacha que es un buen deporte humedecer y amasar harina, sacudir y doblar la ropa.$^{49}$ Incluso le dice que con estas actividades comería más gustosa,

${ }^{47} \mathrm{Cf}$. Xen., Lac., I, 4. Plutarco informa que las espartanas practicaban la carrera, la lucha, el lanzamiento de disco y jabalina (cf. Lic., XIV, 2). García Romero sostiene que las mujeres embarazadas y amas de casa no fueron las únicas que se beneficiaron gracias a la educación atlética espartana. La práctica deportiva y la vida al aire libre de las jóvenes lacedemonias ayudaron a propagar por todos lados la fama de su belleza y salud:

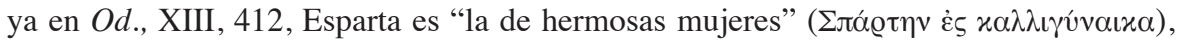
También en Lisístrata, Aristófanes destaca la belleza, el buen semblante y el vigor de la espartana Lampito (vv. 78 ss.). Todo indica que las jóvenes lacedemonias practicaban la carrera, la lucha, el salto y los lanzamientos de disco y jabalina, es decir, el pentatlón completo. Ciertas fuentes antiguas sugieren que la natación e incluso la equitación estaban entre los deportes que ellas realizaban (cf. García Romero s. d., p. 6).

${ }^{48}$ Las atenienses tenían pocas oportunidades para ejercitarse, la danza era una forma y también correr alrededor del altar de Artemisa en Braurón (cf. Pomeroy 1994, p. 307).

${ }^{49}$ Cf. Oec., X, 10-11. Conforme a lo estipulado por la ley y los dioses, es más honroso que la mujer permanezca dentro de su casa, no en el quicio de la puerta (ibid.,

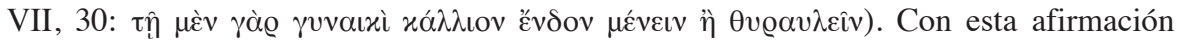
se evita que la mujer salga y tenga amigas: "la amistad entre mujeres normalmente resulta peligrosa, ya que fomenta el engaño y la inestabilidad de la lealtad femenina a los valores masculinos que fundamentan el orden doméstico" (Picazo Gurina 2008, p. 
estaría más sana y tendría mejor color. ${ }^{50}$ Esta última parte hace traer a la memoria un pasaje de la Constitución de los lacedemonios, donde el autor comenta que Licurgo observó que quienes practican ejercicio tienen buen color, buenos músculos y son robustos; mientras los que no se ejercitan están hinchados, son torpes y débiles. Al hacer ejercicio se garantiza el buen estado físico. ${ }^{51}$ Conviene añadir que las espartanas eran célebres por su belleza, de ahí era Helena; ellas no necesitaban cosméticos para tener una hermosa complexión. ${ }^{52}$

- Desde el inicio del Económico, Jenofonte menciona entre los peores vicios a la pereza ( $\left.\alpha_{\varrho} \gamma i ́ \alpha\right)$, la molicie ( $\left.\mu \alpha \lambda \alpha x i \alpha\right)$ y la negligencia $(\dot{\alpha} \mu \varepsilon \dot{\varepsilon} \varepsilon \varepsilon \alpha),{ }^{53}$ por eso propone un modelo de mujer trabajadora, semejante a la abeja reina. ${ }^{54}$ Aunque la mujer ideal pasa todo el tiempo en su hogar, esto no quiere decir que permanezca sin hacer nada; por el contrario, siempre está ocupada. Mientras la mujer en verdad bella se parece a la abeja, la moralmente fea es similar a los zánganos, seres inútiles que les roban a las abejas el alimento reunido con mucho esfuerzo; Iscómaco asevera que hay que extirparlos cuanto antes de las colmenas. ${ }^{55}$

39). Semónides señala que la mujer-abeja evita las conversaciones frívolas de sus con-

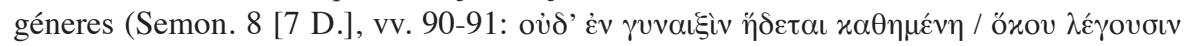

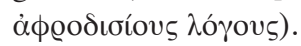

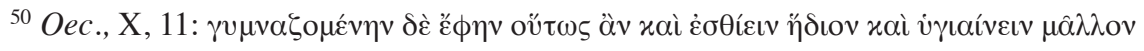

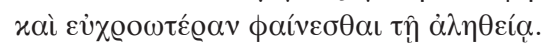

${ }^{51}$ Cf. Lac., V, 8.

${ }^{52}$ Cf. Fantham et al. 1994, p. 57. Jenofonte presenta a otra esposa modelo que no necesita maquillarse, Pantea, a quien describe como la mortal más hermosa de Asia (cf. Cyr., IV, 6, 11, y V, 1, 7).

${ }^{53}$ Oec., I, 19. Los antiguos griegos eligieron el modelo de mujer trabajadora, porque la ociosidad femenina estaba ligada al placer (cf. Papadopoulou-Belmehdi 1996, p. 33).

${ }^{54}$ Cf. Oec., VII, 17. Sobre la comparación entre la mujer y la abeja, cf. VII, 32-34. La esposa de Iscómaco recuerda a la mujer-abeja, porque está en contra del derroche y la glotonería, de allí el énfasis en educarla para que no despilfarre (cf. Iriarte 2001, p. 274). El hecho de que Jenofonte establezca una analogía entre la mujer virtuosa y la abeja tiene un gran simbolismo, pues "las abejas del monte Himeto estaban protegidas por los dioses [...], se relacionan con la crianza de Zeus cuando estaba oculto en un monte de Creta para librarse de ser devorado por Crono, y varios de los personajes que aparecen en este mito tienen nombres derivados de $\mu \varepsilon ́ \lambda \iota \sigma \sigma \alpha$. Según nos cuenta Apolodoro, reinaba en la isla el rey Meliseo (cf. Apollod., 1.6), cuyas hijas, Adrastea e Ida, llamada en otros autores Melisa, cuidan al niño; y Meliseo es también el nombre de uno de los Curetes encargados de la crianza del dios" (Egoscozábal 2003, p. 22).

${ }^{55}$ Cf. Oec., XVII, 14-15. 
También Hesíodo estableció una antítesis entre el zángano y la abeja, donde la mujer es un ser inútil como los zánganos en las colmenas. ${ }^{56}$

El símil entre la mujer y la abeja se remonta a Semónides de Amorgos, quien afirmaba que únicamente este tipo de mujer hace feliz a su esposo, porque no se presta a las murmuraciones y concibe una hermosa prole. Gracias a su trabajo y cuidado se incrementa el patrimonio familiar, quiere a su marido y éste la ama, envejecen juntos. Sólo ella es ilustre y la rodea un halo divino, además le desagrada la plática superflua de sus congéneres. ${ }^{57}$

A mi juicio, el paradigma de la mujer-abeja refleja la animadversión hacia las mujeres de buena posición económica que no trabajaban, sino que vivían en la casa como perezosos parásitos; a esto se debe la insistencia en que la mujer realmente bella se distinga por ser hacendosa y productiva en todos los aspectos. ${ }^{58}$

Aunque la mayoría de autores griegos menospreciaban el trabajo femenino, Jenofonte reconoce que complementa al del hombre y es igualmente valioso, por eso, para el historiador, el trabajo y la belleza feme-

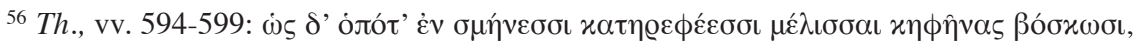

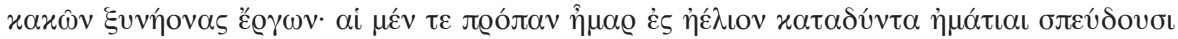

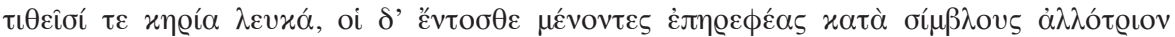

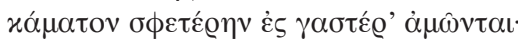

${ }^{57}$ Cf. Semon. 8 [7 D.], vv. 83-93.

${ }^{58}$ Cf. Oec., VII-X, y Mem., II, 7, 7-10. Por lo general, "las labores femeninas se consideran siempre como tareas de larga duración, continuas, porque diario hay que preparar comida y deben elaborarse telas con cierta regularidad. La adecuada realización de dichas actividades tiene connotaciones morales debido a que evitan que las mujeres se comporten como heteras y prostitutas [quienes tejen sólo como distracción]" (Papadopoulou-Belmehdi 1996, p. 18). Tiempo después, "los platos de comida rápidamente preparados solían ser llamados en la lengua de la poblacion griega de Asia Menor 'comida de prostitutas'. También en este caso acortar el tiempo del trabajo femenino considerado socialmente respetable merecía una clara repulsa. Esos trabajos pseudofemeninos pueden haber sido realizados por mujeres cuya actividad sexual y, por tanto, su situación social, representa la inversión del papel de las mujeres ciudadanas. Hay en las fuentes griegas huellas de una consideración sobre el tiempo femenino de trabajo que representa un claro intento de mantener el control sobre el ritmo (<apropiado>, para las mujeres. Frente al tiempo de la acción exterior que es masculino, se ubica el tiempo de la pasividad incesantemente ocupada, que es femenina. Las mujeres griegas están ligadas, sea cual sea la clase social a la que pertenecen, a la ejecución de tareas relacionadas con el mantenimiento de la unidad familiar, en un tiempo largo y continuo" (Picazo Gurina 1995, pp. 18-19). 
nina van unidos de la mano. ${ }^{59}$ Según este autor, fueron los propios dioses y la ley quienes establecieron que la ciudadana se encargue de la crianza de los recién nacidos, la molienda del grano para hacer pan y la elaboración de vestidos de lana. ${ }^{60}$

- Para el historiador, la actitud de la joven realmente bella se caracteriza por su prudencia y moderación. Esto implica mantener una conducta mesurada ante la comida y no dejarse llevar por el impulso sexual. ${ }^{61}$ Desde su hogar paterno la mujer del hacendado está acostumbrada a no sucumbir frente a la gula. ${ }^{62}$ Como $\gamma \alpha \sigma \tau \eta \dot{o}$, significa al mismo tiempo "estómago" y "útero", la capacidad sexual femenina es descrita como glotonería, de ahí que los varones censuren el apetito de las mujeres. En este sentido, Jenofonte sigue hasta cierto grado la tradición, pues para él

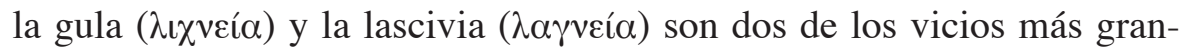
des que avasallan a los seres humanos, sean hombres o mujeres. ${ }^{63}$

En el Económico se percibe un eco de Hesíodo, quien asocia la gula con el desenfreno sexual femenino. El poeta beocio alude a la mujer como un vientre insaciable tanto en la alimentación como en el sexo. Para él, la mala esposa siempre está al acecho de la comida, consume a su marido y le ocasiona una vejez prematura; ${ }^{64}$ por eso mismo se refiere

${ }^{59}$ Cf. Oec., X, 10-13. En la cerámica ática el trabajo y la belleza se relacionan estrechamente con el sexo y el matrimonio. Desde esta perspectiva, la mujer trabajadora resulta sexualmente más atractiva y, por consiguiente, más apropiada para la reproducción. Es así como la producción de objetos se vincula con la producción de cuerpos (cf. Mirón Pérez 2007, p. 278).

${ }^{60}$ Cf. Oec., VII, 16 y 21. La misma Atenea le enseñó a Pandora el arte de tejer (cf. Hes., Op., vv. 63-64). Lo más valioso de esta labor era el tiempo que la mujer invertía en dicha tarea, esto era sinónimo de virtud (cf. Mirón Pérez 2007, p. 278). El telar, asociado con Atenea, evita que las jóvenes sucumban ante Eros y Afrodita (cf. Papadopoulou-Belmehdi 1996, pp. 35 y 38, el tejido implica un ejercicio de moral).

${ }^{61}$ Cf. Iriarte 2001, p. 274. Entre los principales defectos que Aristófanes nota en las mujeres están el ser adúlteras, ninfómanas, amantes del vino, traidoras, charlatanas, inútiles, azote de sus maridos (cf. Thesm., vv. 383-432). Conviene precisar que la codicia, la glotonería y la coquetería femeninas estaban entre los vicios que los antiguos griegos atribuían a Pandora y a las prostitutas.

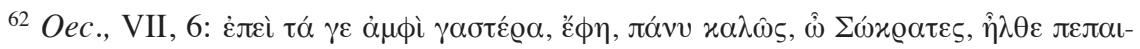

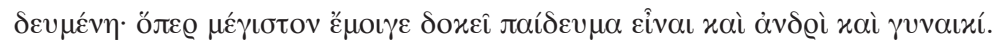

${ }^{63}$ Cf. ibid., I, 22.

${ }^{64}$ Cf. $O p$., vv. 702-705. Semónides comenta que la mujer-asno come de noche y de día y acepta tener relaciones sexuales con cualquier hombre (cf. Semon. 8 [7 D.], vv. 46-49). 
a las hijas de Pandora como compañeras de la saciedad, no de la pobreza. ${ }^{65}$ Las compara con los zánganos y dice que ellas devoran el alimento que las abejas recolectan con tanto trabajo. ${ }^{66}$

Por lo que se refiere estrictamente a la gula, mientras en Lacedemonia las jóvenes recibían una ración de comida similar a la de los varones, Jenofonte señala que en otras ciudades tanto a las embarazadas como a las muchachas bien educadas se les daba una porción muy pequeña y lo menos condimentada posible. ${ }^{67}$

En aquella época se pensaba que las mujeres eran seres débiles que estaban a merced de sus emociones. Los varones temían esa conducta irracional y su inclinación a dejarse llevar por sus pasiones, porque veían la amenaza latente de que en algún momento la mujer introdujera a un hijo ilegítimo en el oikos. Como afirma Picazo Gurina:

La importancia de la castidad no estaba relacionada con la "pureza femenina" sino con el hecho de que un buen comportamiento sexual como esposa garantizaría la legitimidad de los hijos. Y esa preocupación explica la relevancia de las leyes relacionadas con el adulterio en la ciudad griega. ${ }^{68}$

Por eso en Atenas se les exigía a las mujeres, sobre todo a las ciudadanas, una conducta recatada. A la mujer se le inculcaba el aiঠôs,

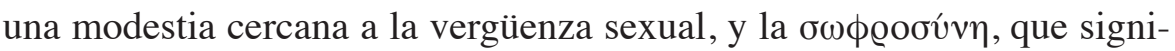
ficaba "discreción" y "dignidad". Bajar la cabeza y los ojos al estar en público o frente a un varón era la mejor forma de mostrar estas virtudes

${ }^{65}$ Cf. Hes., Th., vv. 590-593.

${ }^{66}$ Cf. ibid., vv. 594-599.

${ }^{67} \mathrm{Cf}$. Lac., 1, 3. Algunos datos sugieren que en las casas griegas las mujeres recibían una cantidad menor de alimentos y "antes de comer tenían que esperar a que los miembros más importantes de la familia, es decir, los hombres, hubieran recibido su parte" (Picazo Gurina 2008, p. 43).

${ }^{68}$ Picazo Gurina 2008, p. 66. Para más detalles acerca de las mujeres como esclavas de su instinto sexual, cf. ibid., pp. 42-43, 67; Pomeroy 1999³ , p. 81, y González Almenara 2003, p. 364, n. 860. Entre los castigos que recibía la adúltera estaban los siguientes: era devuelta a su hogar paterno; se le prohibía entrar a los santuarios y, si proseguía con sus actividades religiosas públicas, se exponía a todo, menos a la muerte. Esto era similar a la atimía masculina. El objetivo consistía en colocar a la mujer adúltera al mismo nivel de las heteras o extranjeras, incapaces de engendrar futuros ciudadanos (cf. Picazo Gurina 2008, p. 69). Para más datos sobre la continencia sexual femenina y la legitimidad de los herederos, cf. Gómez Rodríguez 2000, p. 150. 
tan valoradas en la antigua Grecia. ${ }^{69} \mathrm{Al}$ respecto, cuando los hombres de Ciro toman como cautiva a Pantea, ella permanece con la mirada en el suelo y con actitud modesta. ${ }^{70}$ Con el paso del tiempo, el mejor amigo de Ciro se enamoró de esta mujer no sólo a causa de su belleza, sino también por su $x \alpha \lambda o x a ̉ \gamma \alpha \theta i ́ \alpha .^{71}$

Por su parte, la esposa de Iscómaco manifiesta una conducta reservada, ya que desde niña su madre le enseñó que tenía que ser discreta

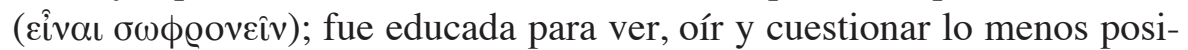
ble. ${ }^{72}$ Sobre esto, en el Discurso fúnebre de Pericles se especifica que la máxima gloria de la mujer consiste en que se hable lo menos posible de ella, porque no debe dar pie a elogios ni a vituperios. ${ }^{73}$ A partir de en-

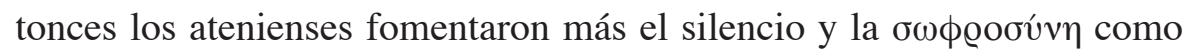
cualidades femeninas.

Acerca de su postura ante los placeres, la mujer virtuosa se caracteriza

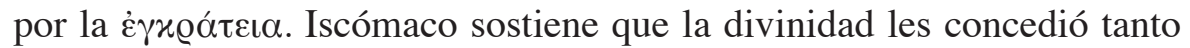
al hombre como a la mujer la facultad de practicar dicha virtud. ${ }^{74}$ En torno a esto, Pantea es un modelo de fidelidad conyugal, pues aunque se encuentra en cautiverio no acepta la propuesta amorosa de Araspas; debido a su lealtad y amor, se suicida sobre el cadáver de su esposo Abradatas. $^{75}$

- En cuanto al atuendo, Jenofonte señala que los espartanos no utilizan vestidos suntuosos, ya que nada más se engalanan con el perfecto estado físico de su cuerpo. ${ }^{76}$ Acorde con esto, el autor asevera que el propio porte marca la distinción entre la mujer virtuosa y las esclavas, porque su aspecto más limpio y su manera de vestir con mayor recato la

${ }^{69}$ Cf. Picazo Gurina 2008, pp. 146-147.

${ }^{70}$ Cf. Cyr., V, 1, 4-5.

${ }^{71}$ Cf. ibid., V, 1, 18.

${ }^{72}$ Cf. Oec., VII, 5 y VII, 14. La casada sobresale por su conducta reservada y sosegada, propia de una mujer honrada de condición libre (cf. González Almenara 2007, p. 46).

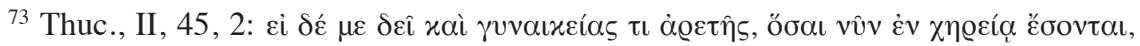

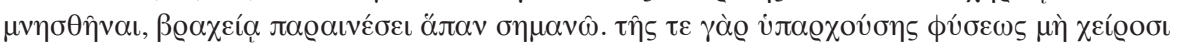

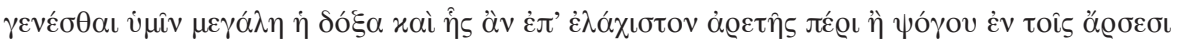

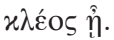

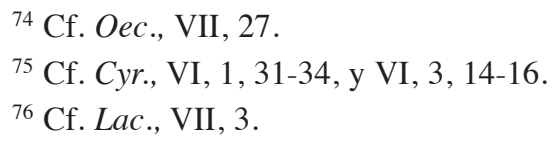


diferencia también de las mujeres acicaladas y embusteras. ${ }^{77}$ Este pasaje coincide con la escena donde la hermosa cautiva Pantea está sentada en el suelo con sus sirvientas y viste igual que ellas, pese a eso los soldados de Ciro de inmediato se dan cuenta de que ella es la señora, gracias a que era más alta, a su virtud y a su decoro. ${ }^{78}$

En Memorables, Jenofonte le atribuye a la mujer decente un aspecto sobrio y un ropaje blanco; mientras la mujer malvada porta un vestido insinuante. ${ }^{79} \mathrm{Al}$ contrario de la actitud pudorosa y recatada de la mujer honorable, la hetera exhibe sus encantos ante los varones; mientras la ciudadana procura pasar inadvertida, la hetera busca llamar la atención y hacerse visible para conseguir clientes.

Durante la época clásica las mujeres respetables llevaban vestidos de lana o sobre todo lino, mientras las heteras utilizaban materiales transparentes, "como la gasa, teñidos de color azafrán. Seguían el estilo de los vestidos jónico o dórico". ${ }^{80}$ Esta última clase de mujeres sentía una especial predilección por las prendas de seda

cuya calculada transparencia permitía velar los encantos resaltándolos al propio tiempo. Cuando no había seda, usaban lino fino de la isla de Amorgos para conseguir el mismo efecto: parecer desnudas a la distancia [...]. Conocedoras de la efectividad de la belleza y la coquetería, las hetairas usaron esas armas con ingenio [...]. Lo excesivo y complejo de su arreglo es a veces motivo de crítica en los textos conservados. ${ }^{81}$

Por lo que concierne a la indumentaria llamativa utilizada por las heteras, cuando Dioniso aparecía en escena portaba una seductora túnica femenina teñida de amarillo anaranjado: rrokotós $^{82}$ La belleza física y la

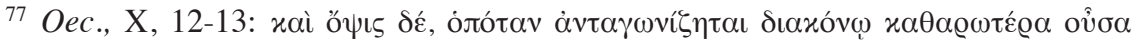

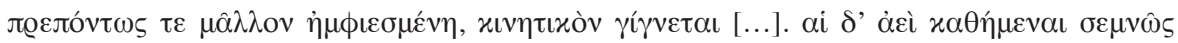

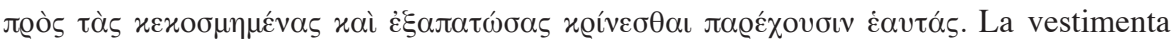
femenina simboliza, en su aspecto positivo, el honor que, en forma de púdica dignidad, tiene que distinguir a doncellas y esposas (cf. Iriarte 2003, p. 283).

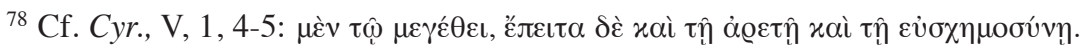

${ }^{79}$ Cf. Mem., II, 1, 22.

${ }^{80}$ Pomeroy $1999^{3}$, p. 101. Las ciudadanas tenían que llevar vestimenta adecuada a su honorabilidad; la ropa de las esposas, y de todas las mujeres respetables, tenía que ser lo más discreta posible (cf. González Almenara 2003, p. 366, n. 866).

${ }^{81}$ Castellanos Moreno 2006, pp. 37-38.

${ }^{82}$ De krókos, Crocus sativus: azafrán cultivado (cf. Kriúkova 2008, p. 25). 
juventud se asociaban con los distintos tonos del amarillo y del naranja; el amarillo era el color de la seducción. ${ }^{83}$ El rojo y el púrpura también estaban reservados para las heteras. ${ }^{84}$

\section{Conclusión: Jenofonte y la genuina belleza femenina}

Si bien a lo largo del Económico es evidente que para el historiador la belleza física natural y la virtud están estrechamente unidas, la prueba contundente se encuentra en Memorables donde, a propósito de la elección de Heracles, se le aparecen al joven dos mujeres muy distintas: una encarna a la Virtud, es alta, de bello aspecto y naturaleza noble, adornada con la pureza de su cuerpo, mirada pudorosa, imagen sobria, vestida de blanco y con andar pausado; la otra representa al Vicio, es alta, bien alimentada, robusta y blanda, maquillada para verse más blanca y sonrosada de lo que en verdad era, simulando ser más delgada, con ojos coquetos y un vestido vaporoso que dejaba ver su cuerpo, fascinada con llamar la atención de los varones y encantada con contemplar a cada instante su propia sombra, ésta no duda en acercarse rápidamente al muchacho..$^{85}$

${ }^{83}$ Cf. Kriúkova 2008, pp. 28 y 39. El tinte amarillo-naranja se extraía del azafrán, planta asociada a las mujeres porque era usada para problemas menstruales (cf. Picazo Gurina 2008, p. 60). En la antigüedad el azafrán se empleaba como planta medicinal, como tinte y como perfume (cf. Masvidal y Picazo 2005, p. 137).

${ }^{84}$ Cf. González Almenara 2003, p. 366, n. 866.

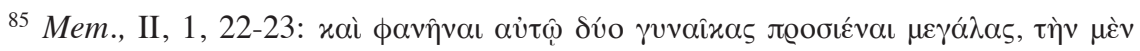

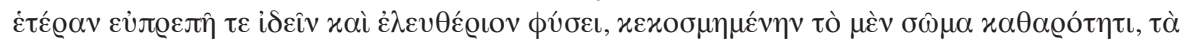

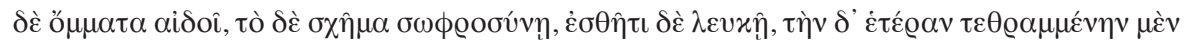

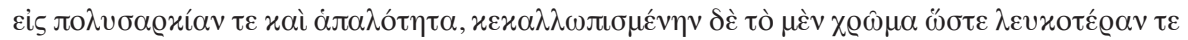

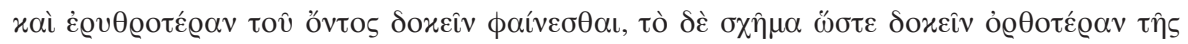

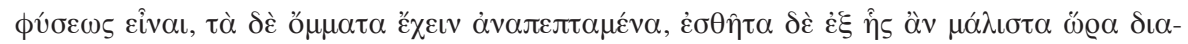

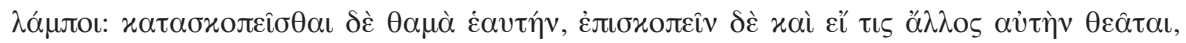

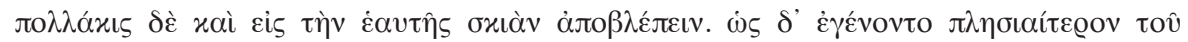

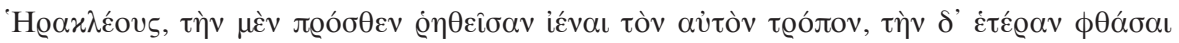

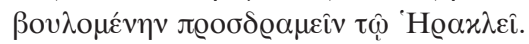

En un artículo donde se aborda la feminización de Narciso, se dice que "si la mujer se recrea en una autocontemplación sin fruto, si no es capaz de engendrar hijos, entonces su belleza no encarna la vida sino la muerte. De ahí, las asociaciones negativas con la muerte, el paso del tiempo, la fugacidad de la vida, con el tema de vanitas en todas sus derivaciones posibles" (Torras 2007, p. 10). 
A partir de lo anterior, cabe deducir que, para Jenofonte, el maquillaje y los artilugios femeninos proporcionan una falsa hermosura, que no precisamente va acompañada de un carácter virtuoso. Desde esta perspectiva, la mujer realmente bella es aquella que manifiesta una congruencia entre su belleza natural y su conducta virtuosa ${ }^{86} \mathrm{La}$ buena presencia física es importante porque el cuerpo es el intérprete de las virtudes femeninas; por este motivo conviene tener un cuerpo disciplinado y productivo en todos los aspectos, alejado de los vicios y la holgazanería.

A pesar de que Jenofonte heredó varios prejuicios, modifica su postura al tomar en cuenta lo aprendido con Sócrates y con los espartanos. Evoca las enseñanzas de su maestro, quien valoraba más la virtud de una mujer real, que la belleza femenina plasmada en una pintura de Zeuxis, rechaza la belleza artificial, porque suele ser engañosa ${ }^{87}$ De acuerdo con el filósofo, lo más seductor, deseable y agradable del ser humano no es su apariencia física, sino el carácter del alma: ${ }^{88}$ es más grato contemplar seres que denotan caracteres bellos, hermosos y amables, que mirar a quienes se comportan de manera fea, malvada y odiosa. ${ }^{89}$ Con base en lo expuesto cabe argumentar que para Sócrates y su discípulo lo más relevante no es la buena presencia física, sino la virtud, la $x \alpha \lambda o x \alpha \dot{\alpha} \alpha \theta \operatorname{cí}^{9} .^{90}$

Desde mi punto de vista, el historiador aprovecha el tema de los cosméticos para contribuir a la $\pi \alpha \iota \delta \varepsilon i ́ \alpha$ femenina, pues mediante la antítesis entre la mujer virtuosa y la hetera difunde su ideal de bella ciudadana, la

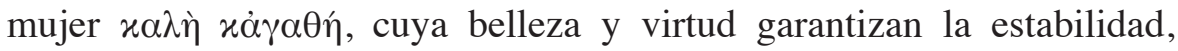
la armonía y la continuidad tanto de su casa como de la sociedad.

${ }^{86}$ En Symp., I, 8, Jenofonte afirma que la belleza es regia, siempre y cuando vaya

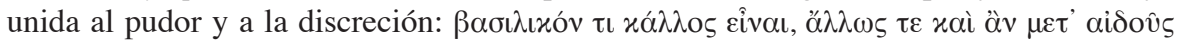

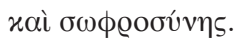

${ }^{87}$ Cf. Oec., X, 1. Zeuxis era de Heraclea, en Lucania. Cuando estuvo en Atenas se volvió muy famoso por sus pinturas de hermosas mujeres. Jenofonte también lo menciona en Symp., 4, 63, y en Mem., I, 4, 3. Dicho pintor estaba a favor del uso del color para la creación de sus bellas obras, aquí Jenofonte alude al uso engañoso de las pinturas, entendidas como cosméticos (cf. Pomeroy 1994, pp. 303-304, y Roscalla, en Senofonte 2000, p. 159, n. I).

${ }^{88}$ Cf. Mem., III, 10, 3.

${ }^{89} \mathrm{Cf}$. ibid., III, 10, 5.

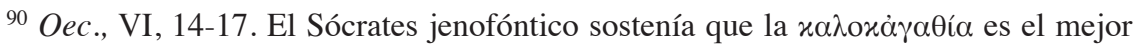
perfume (cf. Symp., II, 4). Para un análisis detallado sobre la esposa de Iscómaco vista como modelo de $x \alpha \lambda$ ox $\alpha \gamma \alpha \theta i ́ \alpha$ femenina, cf. Olivares Chávez 2015. 


\section{BIBLIOGRAFÍA}

\section{Fuentes antiguas}

Aristophanes Comoediae, vol. 2, edition by F. W. Hall and W. M. Geldart, Oxford, Oxford Clarendon Press, 1907.

EuRIPIDIS Fabulae, vol. 2, Gilbert Murray, Oxford, Clarendon Press, 1913.

Hesíodo, Los trabajos y los días, introducción, versión rítmica y notas de Paola Vianello de Córdova, México, Universidad Nacional Autónoma de México, 2007 (2a. reimp. de 1979) (Bibliotheca Scriptorum Graecorum et Romanorum Mexicana).

- Teogonía, estudio general, introducción, versión rítmica y notas de Paola Vianello de Córdova, México, Universidad Nacional Autónoma de México, 2007 (reimp. de 1978) (Bibliotheca Scriptorum Graecorum et Romanorum Mexicana). Homero, Ilíada, libros I-XII, introducción, versión rítmica y notas de Rubén Bonifaz Nuño, México, Universidad Nacional Autónoma de México, 1996 (Bibliotheca Scriptorum Graecorum et Romanorum Mexicana).

- , Ilíada, libros XIII-XXIV, introducción, versión rítmica y notas de Rubén Bonifaz Nuño, México, Universidad Nacional Autónoma de México, 1997 (Bibliotheca Scriptorum Graecorum et Romanorum Mexicana).

-, Odisea, prólogo, versión rítmica e índice de nombres propios de Pedro C. Tapia Zúñiga, estudio introductorio de Albrecht Dihle, México, Universidad Nacional Autónoma de México, 2013 (Bibliotheca Scriptorum Graecorum et Romanorum Mexicana).

Jenofonte, Recuerdos de Sócrates, Económico, Banquete, Apología de Sócrates, introducciones, traducciones y notas de Juan Zaragoza, Madrid, Gredos, 1993 (Biblioteca Clásica Gredos, 182).

Líricos griegos, elegíacos y yambógrafos arcaicos (siglos VII-V a. C.), vol. I, texto y traducción de Francisco Rodríguez Adrados, Barcelona, Alma Mater, 1956.

Plutarch, Plutarch's Lives, english translation by Bernadotte Perrin, CambridgeLondon, Harvard University Press / William Heinemann Ltd., 1914.

SENOFOnTE, Economico, introduzione, traduzione e note di Fabio Roscalla, saggio di Diego Lanza, testo greco a fronte, Milano, Biblioteca Universale Rizzoli, 2000 (2a. ed.).

Sophocles, Ajax. Electra. Trachiniae, Philoctetes, vol. 2, with an english translation by Francis Storr, London-New York, William Heinemann Ltd. / The Macmillan Company, 1913 (The Loeb Classical Library, 21).

ThuCYDIDES, Historiae in two volumes, Oxford, Oxford University Press, 1942.

Xenophon, Memorabilia, Oeconomicus, translation by E. C. Marchant, Symposium, Apology, O. J. Todd, Cambridge, Harvard University Press, 2002 (The Loeb Classical Library).

- Scripta minora, english translation by E. C. Marchant, Cambridge, Harvard University Press, 1946 (The Loeb Classical Library). 
Xenophon, The Education of Cyrus, english translation by Wayne Ambler, New York, Cornell University Press, 2001.

\section{Bibliografía especializada}

Aparicio Villalonga, Catalina, "Friné y Teodota: dos modelos en la Atenas Clásica", Taula. Quaderns de Pensament, 41, 2007/2008, pp. 9-21.

Beltrán Almería, Luis, "Pandora en la encrucijada de los tiempos", Culturas Populares. Revista Electrónica, 2, mayo-agosto, 2006, 9 pp. <http://www.culturaspopulares.org/textos $2 /$ articulos/beltranalmeria.pdf $>$. [Consulta: 4 de marzo de 2015.]

BRASETE, Maria Fernanda, "A crítica às mulheres no fr. 7 de Semónides de Amorgos", en Carlos de Miguel Mora (coord.), Sátira, paródia e caricatura: da Antiguidade aos nossos dias, Aveiro, Universidad de Aveiro, 2003, pp. 39-56.

CAMPS-GASET, Montserrat, "Mythe classique et image féminine dans le poème

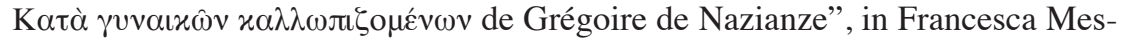
tre and Pilar Gómez (eds.), Three Centuries of Greek Culture under the Roman Empire. Homo Romanus Graeca Oratione, Barcelona, Publicacions i Edicions de la Universitat de Barcelona, 2014, pp. 381-390.

Castellanos Moreno, Ericka, Ecos de Grecia. La designación, el nombre y la voz de la hetaira en el libro XIII de Ateneo, tesis de Maestría en Letras clásicas, México, Universidad Nacional Autónoma de México, 2006.

Colombani, Maria Cecilia, "Mujer-poder y saber. Los pliegues de la arqueología", VIII Congresso Iberoamericano de Ciência, Tecnologia e Gênero, Brasil, Universidade Tecnológica Federal do Paraná, 5 a 9 de abril, 2010, pp. 1-10.

Difabio de RaImondo, Elbia Haydée, "Belleza física femenina en el mito griego: ¿premio o castigo?", ITER Encuentros: La idea de la belleza en la antigua Hélade, XIV, 2006, pp. 69-89.

Dowden, Ken, "Chapter 3. Approaching women through myth: Vital tool or selfdelusion?", in Richard Hawley and Barbara Levick, Women in Antiquity: New Assessments, London-New York, Routledge, 1995, pp. 44-57.

EgoscozÁbal, Cristina, "Los animales del 'Yambo de las mujeres' de Semónides", Estudios Clásicos, 23, 2003, pp. 7-25.

EsCARTín GuAL, Montserrat, "Pandora y Eva: la misoginia judeo-cristiana y griega en la literatura medieval catalana y española", Revista de Lengua y Literatura Catalana, Gallega y Vasca, XIII, 2007-2008, pp. 55-71.

Fantham, Elaine, Helene Peet Foley, Natalie Boymel Kampen, Sarah B. Pomeroy y H. A. Shapiro, "2. Excursus. Spartan Women: Women in a Warrior Society", in Women in the Classical World. Image and Text, New York-Oxford, Oxford University Press, 1994, pp. 56-67.

Farmacia Museo Aramburu <www.farmacia-museoaramburu.org/exposicion/ancusa-raiz/, s. v. ancusa>. [Consulta: 4 de marzo de 2015.] 
FERNÁNDEZ, Diana, "Vestuario escénico", 2012. <http://vestuarioescenico.wordpress.com/2012/09/26/el-calzado-en-grecia-la-estetica-de-cubrir-los-pies/>. [Consulta: 4 de marzo de 2015.]

Galí Oromí, Neus, "La mimesis de la pintura y la escultura en el pensamiento de Jenofonte", Synthesis, 12, 2005, pp. 1-20.

García Romero, Fernando, "El deporte femenino en la antigua Grecia", s. d., pp.

1-24. <www.ucm.es/centros/cont/descargas/documento12001.pdf>. [Consulta:

15 de marzo de 2015.]

Goldhill, Simon, "6. The Seductions of the Gaze: Socrates and his Girlfriends",

in Vivienne J. Gray (ed.), Xenophon, Oxford, Oxford University Prees, 2010 (Oxford Readings in Classical Studies), pp. 167-191.

Gómez RodríGuez, Amparo, "Lo femenino en el pensamiento y la cultura griega", Ciencia y cultura en la Grecia antigua, clásica y helenística, año VII, septiembre, 2000, pp. 145-169.

GonzÁlez AlmenARA, Guillermina, La presencia femenina en el ámbito privado. Estudio sobre textos griegos de época clásica (Heródoto, Tucídides, Jenofonte), tesis doctoral, Universidad de la Laguna, 2003.

—, "Las asistentas domésticas en Heródoto y Jenofonte", Fortunatae, 18, 2007, pp. 43-48.

GonzÁlez SuÁrez, Amalia, “Aspasia y los epitafios”, en Eulalia Pérez Sedeño (coord.), Conceptualización de lo femenino en la filosofía antigua, México, Siglo XXI, 1994, pp. 45-64.

IRIARTE GoÑI, Ana, "Fronteras intramuros en El Económico de Jenofonte", en Pedro López Barja y Susana Reboreda Morillo (eds.), Fronteras e identidad en el mundo griego antiguo. III Reunión de Historiadores (Santiago-Trasalba, 25-27 de septiembre de 2000), Universidade de Santiago de Compostela-Universidade de Vigo, 2001, pp. 267-279.

- , "El ciudadano al desnudo y los seres encubiertos en la antigua Grecia", Veleia, 20, 2003, pp. 273-296.

Konstan, David, "El concepto de belleza en el mundo antiguo y su recepción en Occidente", Nova Tellus, 30.1, 2012, pp. 133-148.

KriúKovA, Helena S., "Historia del traje escénico: Grecia”, Acotaciones: Revista de Investigación Teatral, 21, 2008, pp. 9-46.

López Melero, Raquel, "Los secretos de belleza en la antigua Grecia”, National Geographic Historia, 80, agosto, 2010, pp. 22-25.

Masvidal, Cristina, y Marina PicAzo, Modelando la figura humana. Reflexiones en torno a las imágenes femeninas de la antigüedad, Barcelona, Quaderns Crema, 2005.

Mirón PÉrez, Ma. Dolores, "Los trabajos de las mujeres y la economía de las unidades domésticas en la Grecia Clásica”, Complutum, 2007, 18, pp. 271-280.

- , "Afrodita y las reinas: una mirada al poder femenino en la Grecia helenística", Feminismo/s, 20, diciembre 2012, pp. 165-186.

Molas Font, Maria Dolors, "V. Prostitutas y adúlteras. Cuerpos usados y espíritus seducidos", en Maria Dolors Molas Font, Sonia Guerra López, Elisabet 
Huntingford Antigas y Joana Zaragoza Gras, La violencia de género en la antigüedad, Madrid, Instituto de la mujer, 2006, pp. 109-134.

OмAтоs, Olga, "Misoginia en la tradición literaria griega", Fortunatae: Revista Canaria de Filología, Cultura y Humanidades Clásicas, 4, 1992, pp. 163-181.

Olivares Chávez, Carolina, "La esposa de Iscómaco: modelo de kalokagathía femenina”, en Víctor Hugo Méndez Aguirre y Martha Patricia Irigoyen Troconis (eds.), Mujeres en Grecia y Roma y su trascendencia: diosas, heroínas y esposas, México, Universidad Nacional Autónoma de México, 2015 (Cuadernos del Centro de Estudios Clásicos, 54).

PALACios, Jimena, "Miradas romanas sobre lo femenino: discurso, estereotipos y representación”, Asparkía, 25, 2014, pp. 92-110.

Papadopoulou-Belmehdi, Ioanna, "Tejidos griegos o lo femenino en antítesis", Enrahonar, 26, 1996, pp. 25-39.

PÉrez Miranda, Iván, "Mito, género y paideia. Reflexiones desde la Historia Antigua”, Foro de Educación, 11, 2009, pp. 241-247.

PiCAzo GurinA, Marina, "Espacios y tiempos de las mujeres griegas en la polis clásica", Duoda. Revista d'estudis feministes, 9, 1995, pp. 15-26.

- Alguien se acordará de nosotras. Mujeres en la ciudad griega antigua, Barcelona, Edicions Bellaterra, 2008.

Pomeroy, Sarah B., Xenophon's Oeconomicus: A Social and Historical Commentary, New York, Oxford University Press, 1994.

-, Diosas, rameras, esposas y esclavas. Mujeres en la antigüedad clásica, traducción de Ricardo Lezcano Escudero, Madrid, Akal, $1999^{3}$.

SAlmon, Pierre, "Grillet, Bernard, Les femmes et les fards dans l'Antiquité grecque. Lyon, Centre National de la Recherche Scientifique, 1975", Kroniek. Revue belge de Philologie et d'Histoire, 55/4, 1977, pp. 1262-1263.

SANCHIS LlOPIS, Jordi, "Las profesionales del sexo en la comedia griega del siglo IV a. C.”, Asparkía, 25, 2014, pp. 48-67.

Too, Yun Lee, "The economies of pedagogy: Xenophon's wifely didactics", The Cambridge Classical Journal, 47, enero, 2001, pp. 65-80.

TorRAs, Meri, "Bellas, sabias, narcisistas, prudentes y vanidosas: feminidades especuladas. Una aproximación al motivo de la mujer ante el espejo", Extravío. Revista electrónica de literatura comparada, núm. 2. Universitat de València, 2007, pp. 5-17. <http://www.uv.es/extravio>. [Consulta: 14 de marzo de 2015.]

ZARAGOZA Gras, Joana, "I. La mujer como sujeto pasivo de la literatura griega", en Maria Dolors Molas Font, Sonia Guerra López, Elisabet Huntingford Antigas y Joana Zaragoza Gras, La violencia de género en la antigüedad, Madrid, Instituto de la mujer, 2006, pp. 15-37. 